\title{
Mammographic screening: measurement of the cost in a population based programme in Victoria, Australia
}

\author{
Susan F Hurley, Patricia M Livingston, Noel Thane, Lichun Quang
}

\begin{abstract}
Study objectives - To estimate the cost per woman participating in a mammographic screening programme, and to describe methods for measuring costs.

Design - Expenditure, resource usage, and throughput were monitored over a 12 month period. Unit costs for each phase of the screening process were estimated and linked with the probabilities of each screening outcome to obtain the cost per woman screened and the cost per breast cancer detected.

Setting - A pilot, population based Australian programme offering free two-view mammographic screening.

Participants - A total of 5986 women aged 50-69 years who lived in the target area, were listed on the electoral roll, had no previous breast cancer, and attended the programme.

Results - Unit costs for recruitment, screening, and recall mammography were $\$ 17 \cdot 54, \$ 60 \cdot 04$, and $\$ 175 \cdot 54$, respectively. The costs of clinical assessment for women with subsequent clear, benign, malignant (palpable), and malignant (impalpable) diagnoses were $\$ 173 \cdot 71, \$ 527 \cdot 29$, $\$ 436 \cdot 62$, and $\$ 567 \cdot 22$, respectively. The cost per woman screened was $\$ 117 \cdot 70$, and the cost per breast cancer detected was $\$ 11550$.
\end{abstract}

Conclusions - The cost per woman screened is a key variable in assessment of the cost effectiveness of mammographic screening, and is likely to vary between health care settings. Its measurement is justified if decisions about health care services are to be based on cost effectiveness criteria.

\section{( F Epidemiol Community Health 1994;48:391-399)}

A health care programme's economic efficiency can be described in terms of its cost effectiveness ratio, defined as the net cost per unit of health outcome. The most useful health outcome units for comparisons of the efficiency of programmes are the life year saved and the quality adjusted life year (QALY) saved, but intermediate outcomes, such as the number of cases of disease detected or admissions to hospital avoided can also be used. In view of current interest in allocation of health care resources to programmes on the basis of economic efficiency, ${ }^{1}$ accurate assessment of the cost effectiveness of treatment and disease prevention programmes is important. Calculation of a cost effectiveness ratio involves identification and measurement of both the immediate and consequential health care costs (and savings) associated with a programme, and, similarly, measurement of the programme's short and long term effects on the specified health outcome or outcomes. ${ }^{2,3}$ If consideration of cost effectiveness during resource allocation decisions is to result in a more efficient health care system, both costs and outcomes need to be measured accurately. In many cost effectiveness analyses, however, measurement of costs, in particular, has been fairly cursory. Frequently, costs have been calculated using imputed rather than actual patterns of resource utilisation, ${ }^{4}$ and charges have been used as a surrogate for the true costs of services. ${ }^{5}$ Methods for measuring health care costs have been described, ${ }^{2}$ but may often be difficult to apply, because of limitations in the accounting and workload recording systems of many health care organisations.

In this paper we describe a study of the cost of mammographic screening conducted within a population based Australian programme. There has been considerable interest in the cost and cost effectiveness of mammographic screening, as its widespread implementation is likely to involve substantial expense for governments or health insurance organisations. Cost effectiveness ratios of $£ 3044(1983-84)^{6}$ and US $\$ 4850(1988)^{7}$ per life year gained have been calculated for triennial and biennial screening, respectively, of women aged 50 and over. These figures suggest that mammographic screening is an efficient use of health care resources, compared with many other accepted treatment and prevention programmes. However, the cost of the screening process is a key variable in estimation of mammographic screening's cost effectiveness ratio, ${ }^{4}$ and is likely to vary across health care settings. Our main aim was therefore to measure the cost per woman screened in a pilot mammographic screening programme. We also estimated the cost per case of breast cancer detected. In addition to reporting the cost estimates derived, we describe in some detail the methods used to measure costs.

\section{Methods}

SETTING

Six pilot projects offering free mammographic screening had been established independently in Australia by 1989 . These aimed to study the costs of mammographic screening, the acceptability of screening to Australian women (as 
measured by attendance rates), and standards of service delivery (as measured by recall rates, surgical biopsy rates, and the positive predictive value of screening).

The study described in this paper was conducted within the state of Victoria's pilot project, the Essendon Breast $\mathrm{X}$ ray Programme. Other studies relating to the cost effectiveness of recruitment activities, ${ }^{8}$ and the personal costs incurred by women attending the programme, 9 have been reported. The programme was a joint venture of the Royal Melbourne Hospital $(\mathrm{RMH})$ and the Anti-Cancer Council of Victoria (ACCV), with RMH responsible for screening, assessment and day to day management, and the ACCV responsible for recruitment, data management, evaluation, and research. The service was located at the Essendon Hospital (a campus of the RMH) and ran for two years, from November 1988 to October 1990. It offered mammographic screening to women aged 50-69 years living in any of 34 postcode areas. Free consequential assessment, apart from surgical biopsy, for women with abnormal mammograms was also provided.

The electoral roll, which includes approximately $85 \%$ of the Victorian population, ${ }^{10}$ was

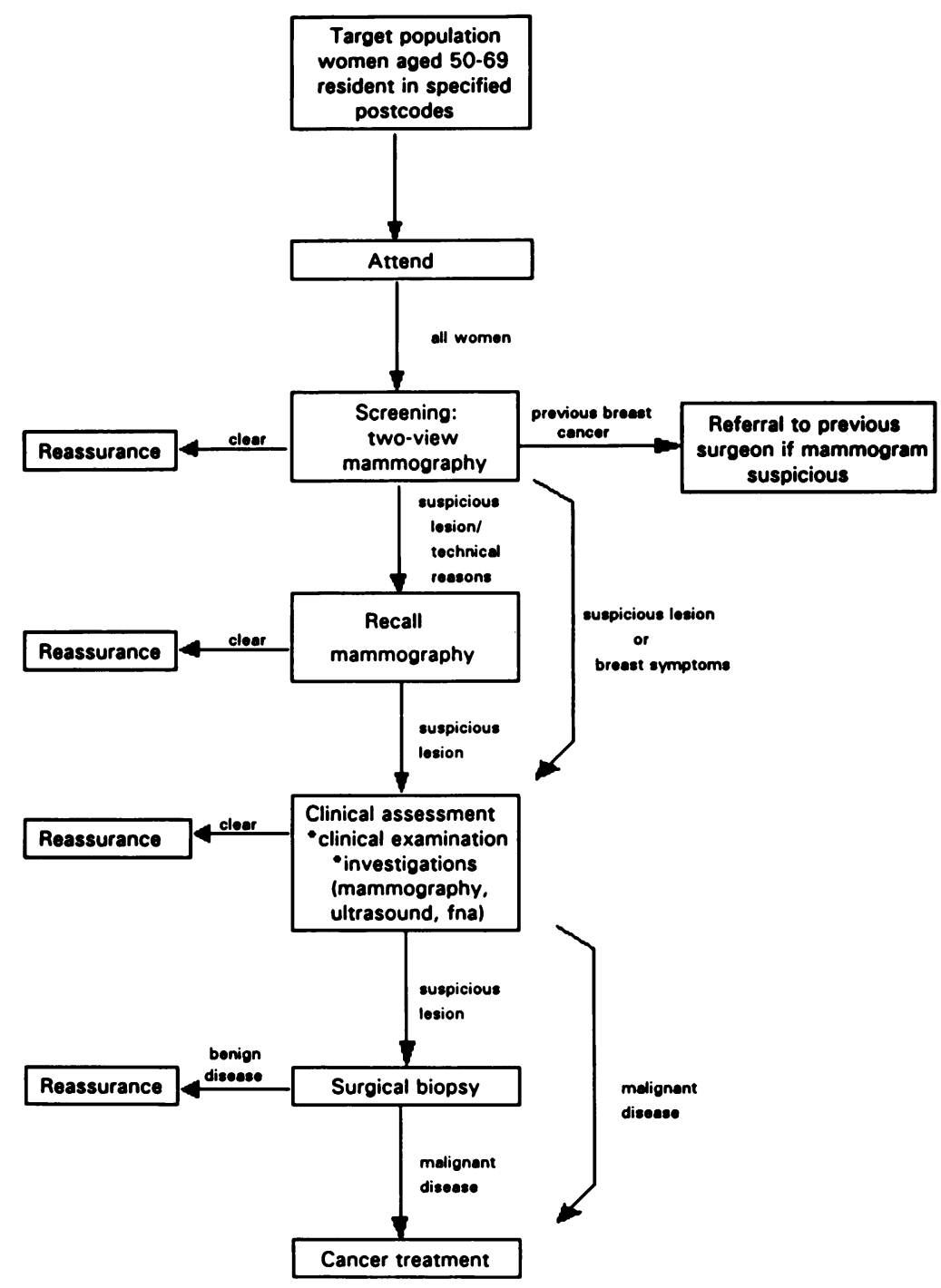

Figure 1 Flow chart for breast $\mathrm{x}$ ray programme screening procedures. chosen as the programme's population list, in order to recruit women and measure attendance rates. There were 43836 women aged 50-69 years living in the target area who were listed on the electoral roll. Although women who were not on the electoral roll were allowed to attend, they were neither actively recruited nor included in calculations of attendance rates.

Both public and personal recruitment campaigns were used to encourage women to attend the programme. ${ }^{8}$ The public recruitment campaign consisted of local newspaper articles, community promotion (displays of motivational material in shops and public places, appointment stalls at shopping centres, and personal contact with community and workplace organisations) and promotion of the programme to general practitioners. The personal recruitment campaign comprised invitation letters to randomly selected women on the programme's population list. Women who did not attend or make an appointment in response to the first letter within four weeks were often sent a follow up letter, and a small sample of women were allocated to telephone follow up.

The programme operated according to a protocol illustrated in figure 1 . Screening was only available by appointment. All women had twoview mammography (a medio-lateral oblique projection and a cranio-caudal projection). The programme had two mammography units, and films were developed using a dedicated processor, before the woman left the programme. Women who reported either a breast lump or bleeding from the nipple were referred for clinical assessment, irrespective of the mammography findings. Mammograms were read independently by two radiologists and each interpretation was recorded. If the mammogram was regarded as normal by both radiologists, the woman was discharged from the programme. If the mammogram was regarded as abnormal, the woman was asked to return for further mammography or for clinical assessment. If there was disagreement between radiologists about the need to recall a woman, a decision was reached after consultation. Recall mammography could include extra, microfocus, or magnification views, after which the woman was either discharged from the programme or referred for clinical assessment. Clinical assessment comprised examination of the breasts by a surgeon, and further investigations if indicated (fine needle aspiration (FNA) biopsy, ultrasound, or surgical biopsy). Counselling services were available at all stages of the screening programme especially during clinical assessment clinics.

\section{Analytical framework}

A model for calculating the cost per woman screened, in the context of cost effectiveness analyses of mammographic screening, was described by Kodlin in 1972, ${ }^{11}$ and subsequently extended by Gravelle et al. ${ }^{12}$ Kodlin and Gravelle $e t$ al consider four possible outcomes from screening: true positive, when screening correctly indicates that the woman has breast cancer; false positive, when screening indicates 
an abnormality but the woman does not have cancer; false negative, when cancer is not detected by screening, but is diagnosed within a specified period, usually one year; and true negative, when the woman does not have breast cancer and has a negative screen. The expected cost of screening a woman is considered to be the probability weighted sum of the immediate and subsequent health service costs for each of the four screening outcome groups, with subsequent costs discounted to their present value according to standard methods. ${ }^{2}$ In a cost effectiveness analysis comparing screening with conventional management, the net cost of screening is calculated by subtracting the expected cost of conventional management from the expected cost of screening a woman.

In our study, we defined the cost per woman screened as the probability weighted sum of the costs of recruitment, screening, recall mammography, and assessment, for true positives, and women discharged from the programme as clear. This definition therefore differed from the more broad definition of Kodlin and Gravelle $e t$ al in three respects. Firstly, the cost of treatment was not considered for any of the outcome groups; secondly, costs for health services unrelated to breast cancer were not considered; and thirdly, false negatives and true negatives were not distinguished (and the cost of assessment for false negatives was therefore not included). Women with breast cancer diagnosed through screening would presumably have had cancer diagnosed at some later time in the absence of screening. Through screening, treatment costs are incurred earlier, and may differ in magnitude because cancer is often diagnosed at a less advanced stage. As estimation of the cost of conventional management was beyond the scope of our study, inclusion of treatment costs would have resulted in overestimation of the expected cost per woman screened. Similarly, the costs of other health care services are only relevant if the costs of conventional management are considered. The assessment costs associated with false negatives were not considered, as data on the number of false negatives were not available within the time frame of this study.

Our study was conducted in two phases. Firstly, unit costs for each component of the screening process, each activity contributing to clinical assessment, and surgical biopsy were estimated. The costs for services provided by the programme were based on expenditures, resource usage, and outputs during the first 12 months of operation. Opportunity costs derived from a number of sources were used to value the services associated with surgical biopsy.

In the second phase, the cost per woman screened, and the cost per case of breast cancer detected were estimated by determining the outcomes for the cohort of eligible women who were screened during the first 12 months. Women were considered eligible if they were aged 50-69 years at screening, lived in the target area, were listed on the electoral roll, and had no history of breast cancer. A record of diagnostic procedures was constructed for eligible women who were referred to clinical assessment, including information on services related to surgical biopsy provided externally. The unit cost data were then linked with the probabilities of each outcome to obtain the cost per woman screened.

The analysis was conducted from the perspective of health service providers, which included the screening service and any centres to which women were referred for surgical biopsy. Costs were expressed in 1989 Australian dollars. Sensitivity analyses were conducted to determine the impact of possible variation in costs and outcome probabilities on the estimates of cost per woman screened and cost per cancer detected.

\section{ESTIMATION OF UNIT COSTS}

Estimation of unit costs for recruitment, screening, recall mammography, and clinical assessment involved four steps which are summarised in figure 2. Briefly, all expenditures and opportunity costs were allocated to eight cost centres within the screening programme (defined as areas of activity for which costs were accumulated). Costs for cost centres which did not provide a measurable service to clients were then reallocated to four service cost centres, and costs for these centres were divided by the number of units of output to estimate the unit costs for each service. A more detailed description of the method follows.

\section{Identification and classification of expenditures and opportunity costs}

Expenditures debited to the programme budget, and any additional resources used but not funded through the budget, were monitored from the time the programme received funding (June 1988) until the end of its first 12 months of operation (October 1989). Non-budgeted costs for research activities were not included. Costs were classified as either recurrent, capital, or establishment.

Recurrent costs were the costs of operating the programme, and were further classified into four groups-staff, advertising, miscellaneous, and overheads. Staff costs comprised salaries for the 11 full time equivalent (FTE) staff paid through the programme budget (a director $(0 \cdot 1$ FTE), a radiologist (0.5FTE), radiographers (1.8 FTE), and a full time manager, counsellor, receptionist, clerk, data entry clerk, state enrolled nurse, education officer, research assistant and project officer) plus salaries for the time spent by additional RMH staff (0.6-1.0 FTE) and ACCV staff $(0.5 \mathrm{FTE})$ who worked on the programme. Advertising costs (for promotional materials) were apportioned equally to months over the periods between reordering supplies. Miscellaneous costs included consumables (film, postage, stationery, telephone), costs for recruitment related travel, and the portions of the costs of ultrasound examinations and cytological examination of fine needle biopsy aspirates which were incurred outside the programme valued according to Medicare (the national health insurance scheme) fees.

Overhead costs related both to the RMH and ACCV. The programme's RMH overheads consisted of administrative costs; an estimated 


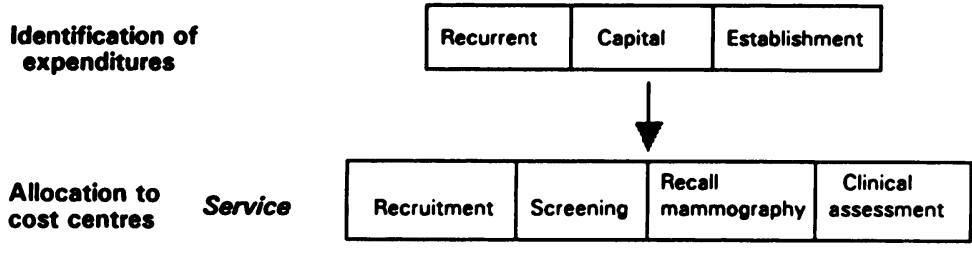

Support

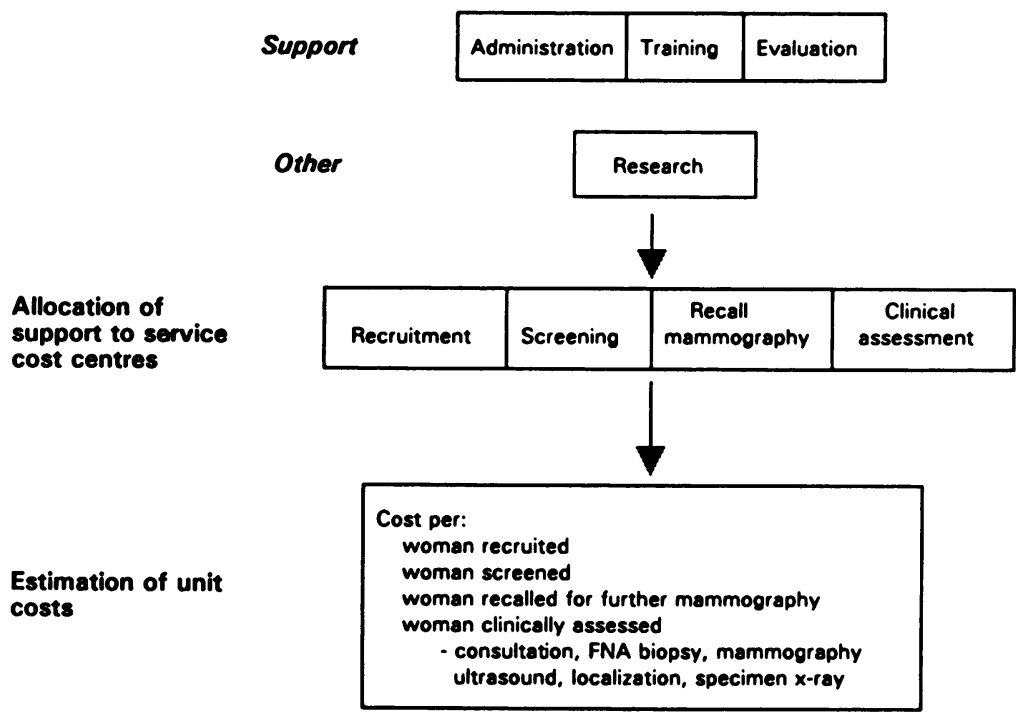

Figure 2 Flow chart summarising method of calculating costs. cellaneous items, and a 5\% per annum cost of capital. ${ }^{13}$

Establishment costs included the cost of staff time to develop the protocol, establish systems for data collection and management, and employ and train staff, the operation of the service for a three-week trial period, and contract computer programming charges for development of the database. One fifth of the establishment costs were allocated to one year of the programme's operation on the assumption that the preparatory work and resource development would enable the programme to operate for five years.

\section{Allocation of costs to cost centres}

Each cost was allocated to one of eight cost centres-four "service" cost centres (recruitment, screening, recall mammography, and clinical assessment), which directly provided services to women; three "support" cost centres (administration, evaluation, and training), which did not provide a measurable service to women; and a research cost centre, which was not regarded as either service or support.

Recurrent costs. Salaries for recruitment staff were allocated on the basis of detailed records of daily activities. Allocation of the salaries of other staff to each cost centre was based on an activity survey in which staff recorded their activities at half hourly intervals for one day per week over two five week periods.

Advertising costs were allocated to the recruitment cost centre. Of the miscellaneous recurrent costs, film costs were allocated to screening, recall mammography and clinical assessment on the basis of the number of films taken during each of these phases of screening. Postage costs were allocated to screening, recall mammography, and clinical assessment on the basis of the number of letters sent after each phase. Half the telephone costs of the screening service were allocated to recruitment and half to administration. ACCV postage, telephone, and travel costs were allocated to recruitment.

RMH overheads were allocated to screening, recall mammography, and clinical assessment on the basis of the proportion of total FTE staff time at the screening site devoted to these cost centres, calculated from the activity survey. Hereafter this allocation basis is referred to as proportional FTE. ACCV overheads were apportioned to recruitment, evaluation, and research.

Capital costs. The annuitised costs of radiological and miscellaneous capital items were allocated to screening, recall mammography, and clinical assessment on the basis of proportional FTE. Ten per cent of computer costs were allocated to the evaluation cost centre and the remaining $90 \%$ were allocated to recruitment, screening, recall, and clinical assessment on the basis of proportional FTE.

Establishment costs. The project officer's salary and contract programming costs were allocated equally to administration and evaluation. The education officer's salary and promotional resource development costs were allocated to recruitment, and other establishment costs were allocated to administration. 
Allocation of support cost centres to service cost centres

The administration and training cost centres were reallocated to screening, recall mammography, and clinical assessment on the basis of each cost centre's paid FTE staff time, as a proportion of the sum of paid FTE for these three service cost centres. The evaluation cost centre was allocated equally to recruitment, screening, recall mammography, and clinical assessment.

\section{Calculation of unit costs}

The sum of expenditures for each cost centre was divided by the number of services to obtain estimates of the costs per woman recruited, screened, recalled for further mammography, and clinically assessed. All women were included, irrespective of age, place of residence, history of previous breast cancer, and inclusion on the electoral roll.

The unit costs of each activity associated with clinical assessment were also calculated. These were: a consultation with a surgeon, mammography, FNA biopsy, ultrasound, hookwire localisation for surgical biopsy, and mammographic examination of biopsy specimens (specimen $x$ ray). The cost of each activity had four components: direct staff costs, indirect staff costs, miscellaneous (activity specific costs), and general costs (consumables, overheads, capital, etc). Direct staff costs for each of the six activities were calculated by asking each staff member to give three estimates of the time they would spend on each activity - the minimum $(a)$, maximum $(b)$, and most likely time $(m)$. The expected time $(t)$ required for each staff member to perform each activity was then calculated using the programme evaluation research technique (PERT) ${ }^{14}$ PERT uses the beta distribution to estimate the expected time for a task according to the formula:

$$
t=\frac{1}{3}\left[2 m+\frac{1}{2}(a+b)\right]
$$

Direct staff costs were then calculated for each activity, using the expected time as a weight (or relative value) to apportion direct staff costs previously allocated to the clinical assessment clinic (CAC) cost centre according to this formula:

$$
D S-\text { cost }_{n}=\sum_{z=1}^{L} \quad\left(\frac{C A C_{z}\left(t_{z n} \cdot \text { volume }_{n}\right)}{\sum_{n=1}^{6}\left(t_{z n} \cdot \text { volume }\right)}\right)
$$

where: $D S-$ cost $_{n}=$ direct staff cost for the nth activity; $L=$ number of staff directly involved in that activity; $C A C_{z}=C A C$ staff cost for the zth staff number; $t_{z n}=$ expected time (minutes) required for activity $n$ by staff member $z$; and volume $_{n}=$ no of activity $n$ during the period.

Indirect staff costs and general costs were apportioned equally to all services. Activity specific costs were the cost of FNA cytology, the equipment, and $\mathrm{RMH}$ radiographer time associated with ultrasound and the cost of film for mammography.

Surgical biopsy involved admission to hospital, surgery, pathological examination of the biopsy specimen, preoperative investigations, drugs, and postoperative medical consultations. We estimated that an inpatient day cost Aus $\$ 317$ and an outpatient visit $\$ 101$ (exclusive of medical care, investigations and drugs) on the basis of RMH expenditures and throughput, using the method of Hull et al. ${ }^{15}$ Medicare schedule fees were used to value surgical procedures; investigations and drugs were valued using data from a concurrent study of the costs of breast cancer recurrences reported previously. ${ }^{16}$

\section{COST PER WOMAN SCREENED, AND COST PER} CANCER DETECTED

The probabilities of progression between phases of the screening pathway were calculated for all eligible women who were screened in the first 12 months. Management details for women referred for clinical assessment were obtained from the database and from women's medical histories at centres where the surgical biopsy was performed. In some instances, surgical biopsy was the only surgical treatment a woman received, and it was therefore difficult to know whether to regard the biopsy as diagnostic or therapeutic. For this study, we classified services used prior to definitive surgery as diagnostic, and services used during and after admission to hospital for definitive surgery as therapeutic. Therefore, if a woman had a provisional diagnosis of breast cancer on the basis of FNA biopsy at the programme and was then referred for a surgical biopsy which was definitive, the surgery was regarded as therapeutic, and costs were not included as diagnostic costs.

The cost per woman screened was then calculated by summing the products of the cost of each phase of the screening process and the probability that a woman progressed to that phase. In other words:

cost per woman screened $=$ recruitment cost + screening cost + (recall mammography cost) $\times$ probability that a woman was referred to recall mammography) + (clinical assessment cost) $x$ (probability that a woman was referred to clinical assessment).

The cost per cancer detected was calculated by dividing the cost per woman screened by the probability of diagnosing cancer in a screened woman.

\section{Results}

UNIT COSTS

The total costs for each of the eight cost centres for the 12 month period are summarised, by expenditure category, in table 1 . The table indicates that screening was by far the largest cost centre. A total of $\$ 193577$ for administration, evaluation and training was then reallocated to screening, recall mammography and clinical assessment. The $\$ 26625$ initially allocated to research was not reallocated to service cost centres. 
Table 1 Programme costs (\$Aus), by cost centre and expenditure category

\begin{tabular}{|c|c|c|c|c|c|c|c|c|c|}
\hline \multirow{2}{*}{$\begin{array}{l}\text { Expenditure } \\
\text { category }\end{array}$} & \multicolumn{8}{|l|}{ Cost centres } & \multirow[t]{2}{*}{ Total } \\
\hline & Recruitment & Screening & $\begin{array}{l}\text { Recall } \\
\text { mammography }\end{array}$ & $\begin{array}{l}\text { Clinical } \\
\text { assessment }\end{array}$ & Administration & Evaluation & Training & Research & \\
\hline \multicolumn{10}{|l|}{ Recurrent: } \\
\hline $\begin{array}{l}\text { Staff } \\
\text { Advertising }\end{array}$ & 53224 & 140505 & 48250 & 45105 & 103857 & 23490 & 5470 & 18716 & 438617 \\
\hline $\begin{array}{l}\text { Advertising } \\
\text { Miscellaneous }\end{array}$ & $\begin{array}{l}30169 \\
11096\end{array}$ & $\overline{45441}$ & $\overline{4521}$ & $\overline{8500}$ & $\overline{3080}$ & - & - & - & 30169 \\
\hline Overheads & 13181 & 91848 & 25663 & $\begin{array}{r}8509 \\
17559\end{array}$ & $\begin{array}{c}32989 \\
-\end{array}$ & $\overline{5273}$ & $\begin{array}{c}5498 \\
-\end{array}$ & $\overline{7909}$ & 108054 \\
\hline Total & 107670 & 277794 & 78434 & 71173 & 136846 & 28763 & $10 \overline{968}$ & 26625 & 738273 \\
\hline $\begin{array}{l}\text { Capital } \\
\text { Establishment }\end{array}$ & $\overline{0}$ & 31339 & 8756 & 5991 & - & 1099 & - & - & 47185 \\
\hline $\begin{array}{l}\text { Establishment } \\
\text { Total }\end{array}$ & $\begin{array}{r}8370 \\
116040\end{array}$ & $30 \overline{1} 133$ & $87 \overline{190}$ & $77 \overline{164}$ & 11852 & 4050 & - & - & 24272 \\
\hline
\end{tabular}

The number of women seen at each phase of screening, and the estimated unit costs for recruitment, screening, recall mammography, and clinical assessment are summarised for each quarterly period and the total period in table 2 . The unit costs for clinical assessment were the programme based costs per woman referred for clinical assessment, and in many instances related to more than one visit. For recruitment and screening, the unit costs for the second and third quarters were lower than the first and fourth quarters, but a strong trend towards decreasing unit costs over time was not evident. However, for recall mammography and clinical assessment, unit costs were substantially lower in the third and fourth quarters, when throughput was greater, compared with the first two quarters.

A sensitivity analysis was undertaken by omitting ACCV overheads, on the basis that the programme could possibly have been administered solely by RMH for the same overhead cost. This reduced the unit costs for recruitment, screening, recall mammography, and

Table 2 Unit costs (Aus\$) and number of women for each phase of the screening process

\begin{tabular}{|c|c|c|c|c|c|c|c|c|}
\hline \multirow[b]{2}{*}{ Period* } & \multicolumn{2}{|c|}{ Recruitment } & \multicolumn{2}{|c|}{ Screening } & \multicolumn{2}{|c|}{$\begin{array}{l}\text { Recall } \\
\text { mammography }\end{array}$} & \multicolumn{2}{|c|}{$\begin{array}{l}\text { Clinical } \\
\text { assessment }\end{array}$} \\
\hline & Cost & No & Cost & No & Cost & No & Cost & No \\
\hline $\begin{array}{c}1 \\
2 \\
3 \\
4 \\
\text { Total }\end{array}$ & $\begin{array}{l}22.43 \\
15.67 \\
16.03 \\
17.85 \\
17.54\end{array}$ & $\begin{array}{l}1229 \\
1829 \\
2096 \\
1944 \\
7098\end{array}$ & $\begin{array}{l}79 \cdot 40 \\
59 \cdot 53 \\
47.92 \\
61.35 \\
60 \cdot 40\end{array}$ & $\begin{array}{l}1229 \\
1829 \\
2096 \\
1944 \\
7098\end{array}$ & $\begin{array}{l}323 \cdot 34 \\
265 \cdot 58 \\
140 \cdot 12 \\
119 \cdot 36 \\
175 \cdot 74\end{array}$ & $\begin{array}{r}91 \\
119 \\
215 \\
292 \\
717\end{array}$ & $\begin{array}{l}293 \cdot 32 \\
296 \cdot 72 \\
213 \cdot 76 \\
213 \cdot 10 \\
252 \cdot 13\end{array}$ & $\begin{array}{r}82 \\
90 \\
123 \\
127 \\
422\end{array}$ \\
\hline
\end{tabular}

*Each quarterly period and the total period

Table 3 Expected times and volumes for clinical assessment activities

\begin{tabular}{lllllll}
\hline & \multicolumn{7}{l}{ Expected time (min) } \\
\cline { 2 - 7 } Activity & Volume $^{*}$ & Surgeon & Radiologist & SEN* & Counsellor & Radiographer \\
\hline Consultation & 517 & 7 & 7 & 6 & 38 & - \\
Mammography & 109 & - & - & 3 & - & - \\
FNA Biopsy & 53 & 5 & - & 5 & - & - \\
Ultrasound & 129 & - & 15 & - & 37 & 41 \\
Localisation & 37 & - & 12 & - & - & 21 \\
Specimen $X$ ray & 36 & - & - & - &
\end{tabular}

*Number of each activity for the 12 month period (number of consultations greater than in table 2 because some women had more than one consultation); $\mathrm{SEN}=$ state enrolled nurse; FNA = fine needle aspiration. clinical assessment over the total period only slightly to $\$ 15 \cdot 50, \$ 59 \cdot 86, \$ 173.90$, and $\$ 249 \cdot 01$, respectively.

\section{COST OF CLINICAL ASSESSMENT ACTIVITIES}

Five staff members - the surgeon, radiologist, state enrolled nurse, counsellor, and radiographer-were directly involved with clinical assessment services. The expected time spent by each staff member on each activity is summarised in table 3 , together with the number of activities performed over the 12 month period. The estimated costs of each activity are summarised in table 4 . The indirect staff costs and general costs were the same for each activity (\$24.16 and $\$ 44 \cdot 17$ respectively).

\section{COST PER WOMAN SCREENED, COST PER CANCER} DETECTED

Over the 12 month period, 5986 women were screened, and the probabilities of referral from phase to phase of the screening process are presented graphically in figure 3 . Of the women screened, $10.9 \%$ were recalled for further mammography, either for suspicion of a lesion or for technical reasons, and a further $2 \cdot 1 \%$ were referred directly for clinical assessment, either because of symptoms on presentation or, more rarely, because of findings on mammography. Of the women who underwent recall mammography, $36 \%$ were referred for clinical assessment, and of women referred for clinical assessment, $48.9 \%$ were discharged with a clear diagnosis, $124(33.9 \%)$ were diagnosed as benign, and $61(16.6 \%)$ were found to have breast cancer. Two women each had two cancers detected. The cancer detection rate was therefore $10 \cdot 2$ per 1000 women per year. Of the 63 cancers detected, 20 were impalpable.

Thirty five of the 124 women with a benign diagnosis had a surgical biopsy. Hookwire localisation was used for 22 of the 35 biopsies with benign results, and for nine of the 61 biopsies with malignant results. During clinical assessment, FNA biopsies were performed for 13 women $(10.5 \%)$ with subsequent benign diagnoses, and 31 women $(50.8 \%)$ with subsequent malignant diagnoses. Ultrasound was performed for 53 of the women $(42 \cdot 7 \%)$ with benign diagnoses and eight of the women $(13 \cdot 1 \%)$ with malignant diagnoses. 


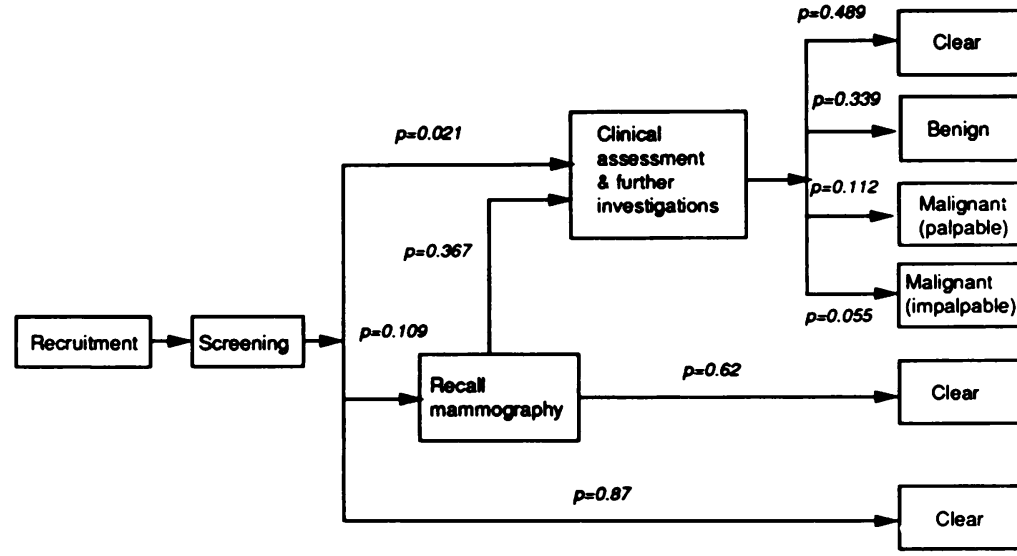

-Probabilities do not sum to 1 for each branch because some women did not complete the screening process.

Figure 3 Summary of outcomes and probabilities for the cohort of eligible women who were screened.
Table 4 Unit costs for clinical assessment activities

\begin{tabular}{|c|c|c|c|}
\hline \multirow[t]{2}{*}{ Activity } & \multicolumn{3}{|l|}{ Cost (Aus\$) } \\
\hline & Direct staff & Miscellaneous & Total ${ }^{*}$ \\
\hline $\begin{array}{l}\text { Consultation } \\
\text { Mammography } \\
\text { FNA biopsy } \\
\text { Ultrasound } \\
\text { Localisation } \\
\text { Specimen } X \text { ray }\end{array}$ & $\begin{array}{l}47 \cdot 18 \\
28 \cdot 65 \\
15 \cdot 78 \\
37 \cdot 37 \\
97 \cdot 96 \\
27 \cdot 79\end{array}$ & $\begin{array}{l}- \\
5 \cdot 20 \\
73 \cdot 00 \\
30 \cdot 80 \\
-\end{array}$ & $\begin{array}{r}115 \cdot 51 \\
102 \cdot 18 \\
157 \cdot 11 \\
136 \cdot 50 \\
166 \cdot 29 \\
96 \cdot 12\end{array}$ \\
\hline
\end{tabular}

*Indirect staff and general costs totalling $\$ 68.33$ were added to each activity's direct staff and miscellaneous costs.

FNA = fine needle aspiration.

creased the cost per woman by only $3 \cdot 1 \%$, and a $10 \%$ increase in diagnosis costs for women with breast cancer increased the cost per woman screened by only $0.4 \%$. A decrease in the cancer detection rate to 7 per 1000 women would increase the cost per cancer detected to around $\$ 16800$.

\section{Discussion}

Complete information about external diagnostic and treatment services could be obtained for 93 of the 96 women referred from the programme ( 58 malignant, 35 benign). Of the 58 women with breast cancer, 44 had surgical biopsy and definitive surgery in a single operation and the remainder were admitted for a diagnostic surgical biopsy before definitive surgery. The mean costs of diagnosis, including programme and external services, for women referred for clinical assessment with subsequent clear, benign, malignant (palpable), and malignant (impalpable) diagnoses were \$173.71, $\$ 527 \cdot 29, \$ 436 \cdot 62$, and $\$ 567 \cdot 22$, respectively. These costs, and the unit costs for recruitment, screening, and recall mammography for the total period (table 2) were then related to the probabilities in figure 3 to calculate the cost per woman screened, according to the formula outlined in the methods section, that is:

cost per woman screened $=$

$\$ 17 \cdot 54+\$ 60.04+(0 \cdot 109 \times \$ 175 \cdot 74)+[0.021+$ $(0.109 \times 0.367)] \times[(0.489 \times \$ 173.71)+$

$(0.339 \times \$ 527.29)+(0.112 \times \$ 436.62)+$ $(0.055 \times \$ 567 \cdot 22)]$

The probability of progressing to clinical assessment was the sum of the probability that a woman was referred directly from screening and the probability that a woman was referred via recall mammography. The cost of clinical assessment was the sum of the costs of each outcome multiplied by the probability of the outcome. The total cost per woman screened was calculated in this manner to be $\$ 117 \cdot 70$. The cost per cancer detected was therefore $\$ 11550$.

Sensitivity analyses were used to investigate the effect of variations in costs and probabilities. The cost per woman screened was sensitive to the unit costs of screening-a $10 \%$ increase in unit costs increased the cost per woman screened by $5 \%$. In contrast, a $10 \%$ change in recruitment costs altered the cost per woman by only $1.5 \%$, a $25 \%$ decrease in the percentage of women recalled for further mammography de-
Our study yielded estimates of the unit costs of each phase of the screening process, the cost per woman screened, and the cost per cancer detected for the first 12 months of operation of a pilot, population based mammographic screening programme. This discussion will focus on the validity of the methods used to obtain these estimates, the projected variations in costs with changing throughput, and the implications of these costs for implementation of mammographic screening services.

Three practical difficulties arise in costing health care: tracking resource usage, apportioning joint resource usage to the appropriate activity, and valuing resources credibly. These problems were minimised in this study because the programme was newly established, and evaluation of costs was an objective from the outset. Hence, accounting systems were established to facilitate economic evaluation and staff were receptive to recording activities. Resource usage was fairly simple to monitor within the programme. However, considerable effort was required to obtain details of management of women referred from the programme for further assessment.

The issue of apportioning joint resource usage to individual activities arose in two ways. Firstly, within the programme, staff, film, and consumables were used for a number of different activities, and apportionment of costs to cost centres was determined through surveys and database records. This apportionment had a potentially big impact on unit costs. Staff costs comprised $54 \%$ of total costs (table 3 ) and were allocated on the basis of activity surveys conducted over 10 working days. As staff performed different activities each day, depending, for example, on whether screening or recall clinics were offered, it was important to obtain measurements of activities on each day of the week and to then determine the proportion of each staff member's time devoted to the defined cost centres. Activity diaries, which were simple and acceptable to staff, were used, but involved possible inaccurate recording of 
information, either inadvertently due to the response burden, or, purposefully due to concerns about the survey. The response burden was minimised by having staff complete the diaries for only one day in any week, and concerns were allayed by involving staff in design of the survey. Other methods for work analysis were considered, including continuous observation, whereby an observer measures the time spent by staff on predetermined categories of activities, and work sampling, which involves an observer recording multiple observations of a staff member's activities at randomly selected times. ${ }^{17}$ Programme staff believed that these methods would be too intrusive and might cause embarrassment to clients. Moreover, in many instances an observer would have been unable to adequately categorise the task being performed, as clerical activities, for example, could relate to any of the cost centres.

Film, postage, and travel costs were allocated to cost centres on the basis of actual usage, but most other costs were allocated to cost centres on the basis of proportional FTE staff time. This was thought to be a reasonably accurate measure of the relative resource usage by different cost centres. The throughput of women for each of the service cost centres was an alternative allocation basis, but would not have reflected the longer time spent with women who were recalled, compared with those who were screened.

The second area where apportioning shared resources was relevant was for resources used jointly by the programme and either $\mathrm{RMH}$ or the ACCV. These were allocated directly to the programme on the basis of proportional FTE. More sophisticated allocation methods, such as step down or simultaneous equation approaches, ${ }^{2}$ which adjust for interactions between the overhead departments, were beyond the scope of the two institutions' accounting systems.

It could be argued that the cost per woman screened of $\$ 117 \cdot 70$, derived on the basis of the first 12 months of screening, represented a start up phase, and that costs would drop once the programme was operating at full capacity. In fact, more than $80 \%$, and often more than $90 \%$ of available appointments were filled almost every week from the fourth month onwards. The number of radiographers was considered to be the main constraint on screening capacity and therefore the radiographer establishment was increased from 1.8 FTE to $3.0 \mathrm{FTE}$ in February 1990. Over the next six months (February-July 1990), 5638 women were screened, and assessed when indicated. This was 1598 women more than the number screened during the final two quarters of the first 12 months. Complete cost and outcome data were not available for this period. However, approximately $\$ 27000$ was spent on the additional radiographer staff and $x$ ray film required to screen these extra women. Assuming that all other costs remained constant, the unit cost of screening for this six month period would be approximately $\$ 42.50$-approximately a $30 \%$ decrease compared with the figure for the first 12 months. Only $8.3 \%$ of women screened over the six month period February to July 1990 were recalled for further mammography. If it is assumed that unit recruitment and diagnosis costs and cancer detection rates were unchanged, the cost per woman screened would be approximately $\$ 96.96$, an $18 \%$ reduction compared with the first year. Programme staff believed that it was extremely unlikely that screening capacity could be increased any further. The only opportunity for further increasing throughput would be a decrease in recall rates, which would make more screening sessions available. The only opportunity for reducing staff costs, which comprised $53 \%$ of total costs, was thought to be reduction in the number of hours worked by the counsellor, as it was thought that her availability for screening sessions was not warranted. However, this would have a negligible impact on screening costs.

Although changes in the cancer detection rate would only have a small impact on the cost per woman screened, they would have a big effect on the cost per cancer detected. The cancer detection rate for the first 12 months of the programme was 10.2 per 1000 women screened. This rate is substantially higher than the maximum cancer detection rate of 7.5 per 1000 women for the controlled trials of screening reported from the Malmö study. ${ }^{18}$ The programme's higher cancer detection rate compared with the Malmö trial could be due to greater sensitivity of mammographic interpretation, possibly resulting from double reporting, or to the mix of recruitment strategies used. Women could attend the programme without receiving an invitation letter, and this may have encouraged symptomatic women to present. Of the 61 women who had breast cancer diagnosed, $12(19.7 \%)$ reported a breast lump or bleeding from the nipple on presentation. If fewer symptomatic women presented during the second year of the prevalence screening round, the cancer detection rate might decrease and the cost per cancer detected would therefore increase.

The importance of detailed costing studies, such as the one we describe, can be seen in relation to plans for expansion of mammographic screening services in Australia. An advisory working party, which recommended a national screening programme, predicted that the gross cost of an organised mammographic screening programme in Australia would be $\$ 10671$ (1989 dollars) per life year saved. ${ }^{19}$ This prediction was based on estimates of the cost per woman screened of $\$ 120$ during the first year, decreasing to $\$ 80$ over five years. Our study suggests that the former estimate is realistic, but the latter is overly optimistic. Careful measurement of costs should become an important component of cost effectiveness analyses.

This work was funded by the Victorian Health Promotion Foundation and the Anti-Cancer Council of Victoria. Susan Hurley is supported by a Neil Hamilton Fairley Fellowship from the National Health and Medical Research Council. We thank Dr David Evans for helpful comments on costing plans and previous drafts, Ms Bronwyn Silver for assistance with graphics, Mr Bill Rae for providing ACCV accounts, and all the staff of the Breast $X$ ray Programme. 
1 Klein R. On the Oregon trail: rationing health care. $B M \mathcal{F}$ 1991;302:1-2.

2 Drummond MF, Stoddart GL, Torrance GW. Methods for the economic evaluation of health care programmes. Oxford: Oxford University Press, 1987.

3 Weinstein MC, Fineberg HV, Elstein AS, Frazier HS Neuhauser D, Neutra RR, McNeil BJ. Clinical decision analysis. Philadelphia: WB Saunders Company, 1980.

4 Eddy DM. Screening for breast cancer. Ann Intern Med 1989;111:389-99.

5 Finkler SA. The distinction between costs and charges. Ann Intern Med 1982;96:102-9.

6 Report to the Health Ministers of England, Wales, Scotland, and Northern Ireland, by a working group chaired by Sir Patrick Forrest. Breast cancer screening. London: Department of Health and Social Security, 1986.

7 van der Maas PJ, de Koning HJ, van Ineveld BM, van Oortmarssen GJ, Habbema JDF, Lubbe KTH, Geerts AT, Collette HJA, Verbeek ALM, Hendricks JHCL, Rombach JJ. The cost-effectiveness of breast cancer screening. Int $\mathcal{f}$ Cancer 1989;43:1055-60.

Reading $D$, Cock burn J, Flint-Richter D. Effectivness, costs and costeffectiveness of recruitment strategies for a mammographic screening program to detect breast cancer. $\mathcal{F}$ Natl Cance Inst 1992;84:855-63.

9 Hurley SF, Livingston PM. Personal costs incurred by women attending a mammographic screening programme. Med f Aust 1991;154:132-4.
10 Hurley SF. Screening: the need for a population register (leading article). Med $\mathcal{f}$ Aust 1990;153:310-11.

11 Kodlin D. A note on the cost-benefit problem in screening for breast cancer. Methods Inf Med 1972;11:242-7.

12 Gravelle HSE, Simpson PR, Chamberlain J. Breast cancer screening and health service costs. $\mathcal{f}$ Health Econ 1982;1:185-207.

13 Richardson AW, Gafni A. Treatment of capital costs in valuating health-care programs. Costs and Managemen Nov-Dec 1983;27-30.

14 Daellenbach HG, George JA, McNickle DC. Introduction to operations research techniques. 2nd ed. Boston: Allyn and Bacon Inc, 1983.

15 Hull RD, Hirsh J, Sackett DL, Stoddart GL. Cost-effectiveness of primary and secondary prevention of fatal pulmonary embolism in high-ris f 1982;127:990-5.

16 Hurley SF, Huggins RM, Snyder RD, Bishop JF. The cost of breast cancer recurrences. Br 7 Cancer 1992;65:449-55.

17 Wirth $P$ Kahn, Perkoff GT Comparability of two methods of time and motion study used in a clinical setting: working sampling and continuous observation. Med Care 1977;15:953-60.

18 Hurley SF, Kaldor JM. The benefits and risks of mammographic screening for breast cancer. Epidemiol Rev 1992:14:101-30.

19 Breast cancer screening in Australia: future directions. Canberra: Australian Government Publishing Service, 1990. 